\title{
Debaixo do palco tem rio
}

\section{Under the stage there is river}

\section{Cafira Zoé}

Cafira Zoé

Cafira Zoé é poeta, multiartista, dramaturga, videógrafa artista visual e de teatro. Atua no Teat(r)o Oficina Uzina Uzona desde 2015.

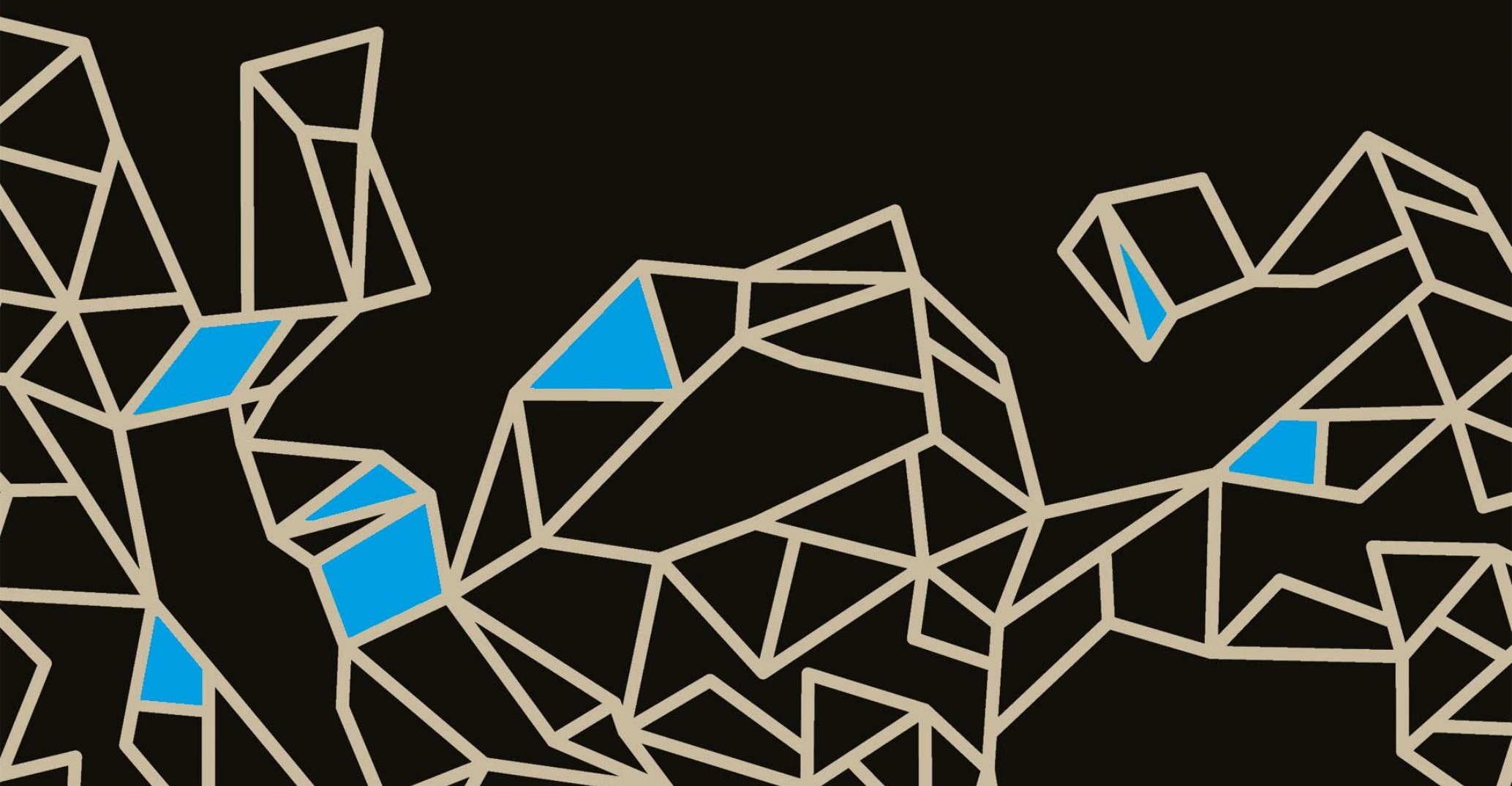



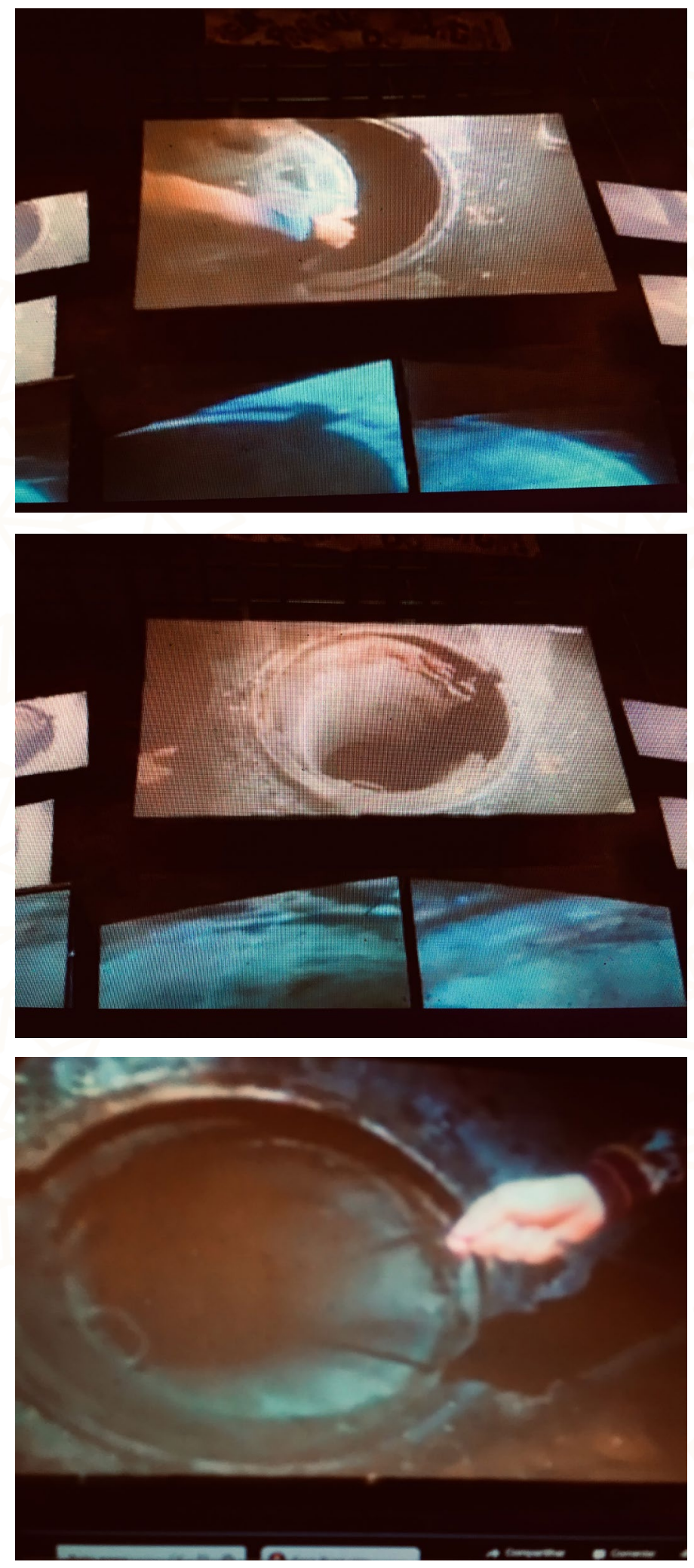

Figura 1 - Tríptico: abertura de galeria do rio do bixiga. a ação é parte dos movimentos pela criação do parque do rio bixiga e pela consequente revitalização do curso do rio que atravessa o território do parque, $4 \mathrm{~m}$ abaixo dos pés - e das patas. 


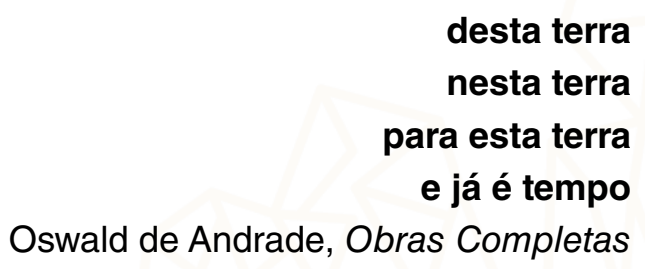

há 40 anos, celebrados no dia 30 de novembro do conturbado ano de 2020, um território de $11 \mathrm{mil} \mathrm{m}^{2}$ no bairro do bixiga reexiste ao avanço da especulação imobiliária compulsória em são paulo. último chão de terra livre no centro da cidade, as terras entre as ruas jaceguai, abolição, santo amaro e japurá, onde habita o teat(r)o oficina - sentinela incansável atento aos movimentos e às ameaças -, são um vale fértil em que se atualiza, ao longo dos anos, uma luta cosmopolítica pela vida.

o cosmos e a política aparentemente não se misturam e, justamente por isso, será preciso operar a transubstanciação de um no outro. uma palavra lava a outra e cria um mundo a partir de uma fricção entre poros. é preciso que as forças cósmicas, potências da matéria, operem por desintoxicação da política como a conhecemos. no teat(r)o oficina falamos muito nessa língua. a política, esse pedaço de carne ferida, precisa de unguentos novos para cicatrizar machucados antigos, feitiços novos para funcionar de novo e em outras formas. se trata também de uma devoração e de um drible epistêmico. não abandonar a palavra, mas lutar por ela. como em alquimia existem as qualidades dos elementos, no candomblé existem as intensidades dos orixás, no teatro existem as forças das entidades, os cavalos que recebem os tremores da cena... em política será preciso limpar as toxinas da palavra para reativar as qualidades adormecidas no tempo:cosmopolítica.

capacidade de capturar, de antenar, de plugar, de ter ressonâncias com potências cósmicas que operem novas forças de poder e poder de transmutação das carcaças fraturadas. proposição de práticas para construir mundos, e mundos em comum, jamais para uma unificação estúpida, acachapante, mas em direção à potencialização dos encontros. conectar práticas no mangue das multiplicidades, num dilatar das coisas para a amplificação total do que "política" nos diz. políticas de instauração contínua de cosmos, de perspectivas e de existências, não mais para segregar, mas para criar composições infinitas. cosmopolítica também são as mãos da minha mãe para cuidar 
da terra; são as práticas do teat(r)o oficina na feituras das peças e na proteção do bixiga; é uma pausa de mil compassos et cetera.

no encontro entre humano e chão, chão e teatro, teatro e cosmos, cosmos e... pequenos brotos de abacate nascendo nas galhadas de um tronco-quase-seco derrubado pela tempestade, a tempestade e o balanço da árvore cesalpina, plantada pelas mãos de lina bo bardi, o balanço e a queda do muro que entremeava o dentro e o fora entre o tronco e a copa - um ato de acupuntura cosmopolítica para abertura dos espaços. esse território está situado em uma parte considerável da planície de inundação do córrego do bixiga, o que se traduz, ao longo dos anos - como em grande parte da cidade de são paulo, construída sobre rios - no comprometimento da permeabilidade dos solos e em outros declives dos processos de uma urbanização fissurada, como enchentes e inundações.

a 4 metros abaixo dos pés - e das patas -, no epicentro nevrálgico dessas terras, corre, confinado em galerias de concreto, o rio do bixiga, cuja bacia vem descendo desde o platô da avenida paulista até desaguar no vale do anhangabaú. é de 1893 o início das obras de retificação do canal, e consequente canalização do ribeirão do anhangabaú, seguidas por processos de canalização subterrânea (tamponamento) dos córregos a ele ligados (itororó, saracura e bixiga) e seus cursos - já na década de 1930 estavam todos totalmente soterrados em galerias.

o que se passa entre o córrego e a terra talvez tenha sido auscultado pelas aves que sobrevoam este espaço aéreo, construindo uma espécie de mapa vital através de rotas de reexistências: dos galhos secos do abacateiro caído, de onde nascem brotos-verde-fluorescentes, até a copa das árvores que vivem no bosque da casa de dona yayá, e de volta, à juba-cheia da cesalpina, fazendo ninhos no teto de vidro do teat(r)o oficina. se estamos atentos, dias imensos de ornitolorgias ${ }^{1}$ serão capazes de captar vibrações dessa atmos-

1 Palavra entre ornitologia - estudo e observação de aves - e orgia - ETIM lat. ōrgĭa,iōrum 'mistérios de Baco'. Nos processos de produção de pensamento do Teat(r)o Oficina, gestados nos ritos teatrais das palavras encarnadas no gesto, diz-se orgia: o carnaval, a multidão num estádio de futebol, o público num teatro de estádio, uma revoada de pássaros, o estouro da boiada, um cardume de peixes... qualquer atmosfera em que se pratique ser muitos, em metamorfoses coletivas. Os limites se confundem, as fronteiras são borradas. Ornitolorgia, assim, flerta com alguma coisa entre o devir-animal e as relações multiespécies: alianças não humanas; observação e incorporação de práticas de existir com, de fazer junto; a revoada dos povos; não é, portanto, termo relativo a prática de atos sexuais entre humanos e pássaros, se porventura lhes ocorreu. 
fera, suas intensidades construindo mundos. num ofício minucioso-poético, imaginar e dar testemunho desses trajetos de fertilização da vida, de biomultiplicidades - eis um trabalho a ser feito. rituais de coexistência, como em alquimia, apontam o percurso da luta neste sítio, encarnada no combate a um modo de vida capital-especulativo nas cidades. parque das terras do bixiga, teatro-parque, lina bo bardi, sítio arqueológico, roça do rio... do bixiga, de são paulo, de um cosmos, em relação com outros cosmos.

auscultar, do latim, auscultare: dar ouvidos, é um termo técnico para a escuta dos sons internos do corpo, que pode ser feita tocando diretamente um corpo com o ouvido ou através de um instrumento conhecido como estetoscópio. consiste em investigar os ruídos dos sistemas circulatório, respiratório e gastrointestinal: uma espécie de escuta dos fluxos subterrâneos, afinal.

no dia 5 de junho de 2019, um rito de acupuntura urbana - o $4^{\circ}$ de grandes proporções na luta pela criação do parque do rio bixiga - lançou uma flecha em direção ao desmassacre desse território: num gesto vital, foi aberto pela primeira vez o bueiro que dá acesso às galerias de concreto que mantém confinado o rio do bixiga, entre as ruas japurá e bixiga, para auscultar ${ }^{2}$ o seu pulso, seiva soterrada. em são paulo, segundo pesquisa do projeto rios e ruas, a qualquer ponto em que pisem os pés - ou as patas -, estamos a 150-200m de um rio. grande parte das ruas por onde vamos são cursos de rios soterrados pela sanha de uma urbanização descabeçada. no bixiga, três rios (saracura, itororó e bixiga) compõem uma bacia hídrica e correm em direção ao vale do anhangabaú, onde antes se formava uma planície fluvial, enterrada na construção da capital que agora sofre com inundações, com desequilíbrios urbanos e com impermeabilidade dos solos, efeitos dos cursos d'água confinados em galerias, asfixiados em canos de concreto ao longo dos anos.

assim como o ruralismo e o agronegócio, a mineração e as barragens, as madeireiras e a exploração de combustíveis fósseis, a especulação imobiliária e a compulsão falocêntrica por torres de cimento que arranham o céu ferem de morte territórios, existências e ecossistemas vitais. a especulação imobiliária constrói cidades para necrose. são áreas ásperas, implantadas de maneira brutal, seja pela demolição desenfreada de construções humanas

2 Para escutar o rio, cf.: RIO BIXIGA. [S. I]: [s. n.], 2020. 1 vídeo (1 min). Publicado pelo canal Parque Bixiga. Disponível em: https://bit.ly/3p2wLfm. Acesso em: 8 fev. 2021. 
e não humanas que-já-não-servem-mais, seja pela criação compulsória de uma arquitetura patriarcal violenta, de constante atualização colonial, especista, segregacionista, sem imersão, relação e simbiose alguma com as biosferas que modificam.

a especulação imobiliária não é um problema das cidades, ou fabricado por elas. a especulação imobiliária é o avanço de um modo perverso, hierárquico e supremacista de fabricar territórios para exploração e, ao mesmo tempo, de determinar os modos como cada vida capturada nos seus limites poderá ou não existir, e onde. ela é máquina de estraçalhamento de subjetividades e de territórios, como a mineração é máquina de comer montanhas inteiras, de forjar abismos secos onde antes existiam vales férteis, de fazer-desaparecer sem precedência picos, geologias e povos inteiros; como o garimpo come terra e florestas; como a monocultura do pensamento, da agricultura e dos modos de vida violam ecossistemas complexos e aniquilam biodiversidades do mangue às cidades; como o fundamentalismo político e religioso mastiga a força vital dos corpos e lhes injeta de volta a grande nódoa corrosiva dos extremismos, entupindo seus poros para a captação das subjetividades da mesma maneira em que soterram as águas urbanas.

a especulação imobiliária avança sobre o bairro do bixiga, em são paulo, avança sobre o território indígena no jaraguá, avança sobre os tupinambás em olivença, na bahia, avança junto com a mineração, sugando minas gerais: é preciso implantar torres de concreto e acabar com o ritmo, com a cultura e com as intensidades locais para receber os operários do massacre geológico e para inaugurar os novos estilos de vida que irão vigorar nas cidades esterilizadas. as cidades também sofrem os efeitos das devastações da ação antrópica na terra. choque séptico nos tecidos urbanos, humanos e não humanos, para espantar todas as potências da diferença. ceder à tara dessa forma de especulação da vida nas cidades e a esse modo de criar o que chamamos cidade é uma maneira de nos entregar às políticas de morte dos tecidos da cidade, da terra, e de nossos próprios corpos. não ceder é uma importante força de vida, potência miúda, talvez, mas que em série e em constelações seja capaz de produzir sinapses suficientes para a criação de tecnologias de lutar-junto, de fazer-junto, de povoar-junto as cidades a partir de um ponto de vida cosmopolítico. 
a luta que se trava nas terras do bixiga, e o movimento que aspira a regeneração ${ }^{3}$ do rio asfixiado, é também uma co-movência, uma força de muitas espécies que se aliam à outras e a muitos outros territórios onde se praticam modos de existir que reexistem - como em guarani se luta: tekoha. são lutas pelo direito à cidade, são lutas dos direitos não humanos; são lutas de imaginação, e de uma imaginação cosmopolítica; são conflitos entre maneiras de existir; são lutas pelo direito de existir de outra maneira; são políticas pela vida; são invenções de mundos, de outras histórias; são fabulações de povos por vir, e que já estão.

mais de 40 territórios compõem a rede de parques de são paulo, que é uma simbiose em luta por áreas verdes-vitais na cidade. a luta dos povos guaranis de são paulo pela criação de um cinturão verde guarani é também uma luta do parque do rio bixiga e deveria ser de toda a cidade. a luta dos povos indígenas pela vida da terra e a marcha das mulheres indígenas, margaridas e campesinas em agosto de 2019, que tomou brasília e ecoou - território: nosso corpo, nosso espírito -, são lutas de aliança. muitas são as tekohas, lugares onde se praticam modos de existir que reexistem: como o jaraguá é guarani, como o teat(r)o oficina é território de luta, como o bixiga é território sagrado - do quilombo urbano do Saracura ao encontro dos povos que forjaram a sua história. denilson baniwa, artista visual e curador, com a sua força gráfica reivindica e instaura:

brasil, terra indígena; são paulo, terra indígena. os assentamentos da reforma agrária na grande são paulo e os grupos de consumo responsável, de comida de luta, que circulam a produção da agricultura urbana agroecológica, são lutas do parque do rio bixiga. os viveiros de sementes e as oficinas de compostagem, que povoam as hortas urbanas, são lutas do parque do rio bixiga. os tupinambás de olivença, na presença de casé angatu tupinambá,

3 No dia 5 de junho de 2019 foi presentificado um projeto, exercício de imaginação política construído a muitas mãos, para um parque do rio do bixiga. Aliança entre Teat(r)o Oficina, artistas + coro de arquitetura cênica, Universidade Antropófaga, Escola da Cidade, sociedade civil, Lina Bo Bardi, Edson Elito, Aziz Ab'Saber e arquitetos/pesquisadores dos córregos da cidade de São Paulo, entre eles Newton Massafumi e Tânia Parma. Nas palavras de Marília Gallmeister, arquiteta do Teat(r)o Oficina, "a grande contribuição desse projeto é levar em conta essa última camada, que, na verdade, é a primeira, a da terra". O córrego é o protagonista, e fazendo eco com Massafumi: ele corta transversalmente o terreno, e, renaturalizado, será cercado de trilhas de terra, em processos de restauração da fauna e flora originais. 
que sagraram o território do teat(r)o oficina e as terras do bixiga com sua dança e seu canto - tupinambá vai te pegá vai te comê, tupinambá vai te pegá vai te comê! - são lutas aliadas a luta pela demarcação do bixiga, patrimônio arquitetônico, arqueológico, artístico, cultural, humano e ecológico de são paulo. carcarás, suiriris, avoantes, papagaios, urubu, bem-te-vi, sabiás-laranjeiras, gavião-asa-de-telha, beija-flor-tesoura... são algumas das espécies que povoam o bixiga e criam rotas invisíveis de manutenção de ciclos vitais, de decomposição e de polinização pelo bairro. há movimentos atuando na restauração de rios, de córregos e de seus cursos na capital. as nascentes do bixiga também fazem parte da história e das riquezas desse bairro fértil do centro da cidade e precisam ser preservadas.

contra todo o confinamento da vida será preciso alegria e coragem, e também poetas, cogumelos e fungos - certas espécies têm a qualidade de acumular resíduos tóxicos e metais pesados em áreas de mineração, assim como em de radioatividade, evitando que os dejetos alcancem a biodiversidade florestal, as plantas, nós. contra toda a asfixia da vida imposta em épocas de políticas estúpidas, banhos de manjericão roxo, de alecrim, de guiné e de sal grosso, verdadeiras tecnologias para espantar os espectros do totalitarismo nos corpos. contra a especulação imobiliária, barricadas de árvores gestando florestas nas cidades. contra a monocultura fundiária e fundamentalista das cidades e do pensamento, será preciso chamar pelos trabalhos dos terreiros que seguram a terra, pelas rezas dos guaranis que seguram quase tudo, pelas palavras-fogo de david kopenawa e pela força da insurreição, onde quer que ela arda: irresistível, indomável. todas essas forças, todos esses povos, humanos e não humanos, os cursos d'água, estão, neste momento, sustentando o céu sobre as nossas cabeças. somos também nós. aqui, agora.

as forças não cessam de compor umas com as outras formas sempre inacabadas, sempre por se fazer, desfazer, destruir, criar, a ponto de um não fixar perene, a ponto de um sempre movediço que opera na fronteira dos contornos, um contínuo infiltrar-se, um incessante fazer-com, com donna haraway: we are humus, not homo, not anthropos; we are compost, not posthuman. a transformação que não se estagna, a agitação e o repouso, o pulso, a composição e a decomposição, o músculo cardíaco, as guelras dos peixes, a pele das cobras, as sístoles e as diástoles, um casulo... talvez a tudo isso se diga: 
é a força vital. aqui, damos testemunho da construção de um mundo. contra soldados de concreto: matas ciliares! barricadas vegetais, minerais, animais, de povos, das mulheres, Igbtq+, indígenas, pretas/es/os, teatros, terreiros, crianças, quilombos, escolas de samba, de soltar pipa, de florestas... água também se planta.

que as forças bandeirantes finalmente cedam às forças da vida e sucumbam, levando junto a insanidade da destruição de São Paulo pelas mãos políticas de construtoras de concreto, abandono e morte.

que a monocultura do pensamento urbanista produtor de hierarquias e desigualdades históricas nos abandone finalmente e São Paulo se encontre com a sua ancestralidade. São Paulo é terra de misturas, de encontros e de uma capacidade de invenção e regeneração infinitas.

que os povos humanos se encontrem com os milhares de rios soterrados e sejam de uma só vez desmassacrados. que o Cinturão Verde Guarani seja reconhecido e preservado. que o Bixiga seja de uma vez por todas protegido das garras do violência imobiliária e tenha suas nascentes, culturas, memórias e povos preservados. que venha o Parque do Rio Bixiga e com ele um pomar urbano e o rio Bixiga a céu aberto para matar a fome a sede e a vontade de criar a vida com arte e teatro com os pés no chão e a companhia das estrelas.

que caiam os patriarcas, os empreiteiros, os falsos-democratas e toda ordem de sanguessugas da nossa adorada terra da garoa e da alegria, e que a eles não sejam mais rendidas nem homenagens nem praças.

Autora convidada 
